\title{
EL LIBRO DE LA ACADEMIA DE LOS NOCTURNOS
}

José María FerRI COLL Universidad de Alicante

La Biblioteca Nacional de España alberga el manuscrito que contiene las actas de las sesiones de la Academia de los Nocturnos (1591-1594). En efecto, el Ms. Res. 32-34 nos permite reconstruir la vida de una academia del Siglo de Oro, y con ello todo un complejo mundo literario donde las relaciones de poder imperantes en la sociedad de entonces se trasladan al seno del cenáculo, de forma que éste se convierte en reflejo de aquéllas. Don Pedro Salvá, que fue propietario de los manuscritos y publicó en 1869 una antología poética extraída de ellos, consideraba que las actas eran el volumen más «precioso» de su biblioteca. Asimismo Ferruccio Blasi, quien dedicó un artículo a la Academia en 1929, aludía al manuscrito denominándolo «rarissimo documento». Contamos con ediciones modernas de algunos textos de la Academia a cargo de Salvá (1869), Martí Grajales (1905-1912), y Zabala (1946); aunque la única elaborada con rigor filológico y que da cuenta tanto de los poemas como de los discursos en prosa de todas las sesiones se debe al esfuerzo de J. L. Canet, J. L. Sirera y E. Rodríguez (1988-)ํ․

Para adentrarse en el mundo de los nocturnos, es necesario esbozar mínimamente la situación sociopolítica en que nació la Academia. El Reino de Valencia en aquellos años era una mínima parte de las posesiones de los Habsburgo de Madrid, quienes a finales del siglo XVI dominaban toda la Península Ibérica, la cuenca occidental del Mediterráneo (Baleares, Sicilia, Cerdeña), algunas plazas italianas (Nápoles, puertos toscanos y ducado de Milán), Tánger, Ceuta, Melilla, Orán, el Franco Condado, los Países Bajos, América central y meridional, Filipinas y todas las colonias portu-

1. Cito por esta edición indicando año, volumen y página, o en su caso, por el manuscrito. 
guesas en América, África y Asia. Gobernar este territorio vastísimo exigía tanto la delegación de poderes, generadora de corrupción y caciquismo, como continuadas inversiones económicas con que pagar a los ejércitos que vigilaban las fronteras y mantenían la paz interna, que duraba muy poco cuando se conseguía su establecimiento. En la década del noventa, las posibilidades de sufragar estos gastos eran muy limitadas, a causa de la extenuación a que habían llegado los distintos reinos de la Monarquía y de la progresiva pérdida del monopolio oceánico a favor de holandeses e ingleses, que comprendieron que la mejor forma de luchar contra Felipe II radicaba en la intromisión en sus dominios transoceánicos. Derrotada la Armada Invencible en 1588, inaugurado en 1590 un nuevo impuesto en Castilla conocido como millones, porque se medía en millones de ducados, y derrotado el sueño imperial de Felipe II, éste tuvo que suspender en 1596 los pagos a sus banqueros, debido a la bancarrota de la Corona. Elliott ilustra esta situación con una parábola quijotesca en que se presenta a «una nación que se había lanzado a su cruzada para acabar comprendiendo que luchaba contra molinos de viento» (1996: 362). Así las cosas, no era extraño que la actividad política de Felipe II y sus gobernadores se ciñera más al ámbito atlántico y europeo que a las tierras que ocupaban los antiguos reinos peninsulares, a los que se dirigía con la intención de conseguir de ellos el sufragio económico de sus empresas. En su nombre, gobernaba el Reino un virrey elegido por él mismo, cuyas funciones han sido resumidas por J. Reglà (1989b: 171). Los primeros virreyes de su reinado eran de origen valenciano. En 1559 nombró al duque de Segorbe, y en 1563 a Joan Llorenç de Vilarrasa. Sin embargo, a partir de 1567, cuando eligió al conde de Benavente, la mayoría de representantes regios en el Reino procedía de la nobleza castellana. En 1581 alcanzó el virreinato Francisco de Montcada, conde de Aitona, quien mantuvo el cargo hasta 1594, coincidiendo, pues, con el cierre de la Academia. Don Francisco se afanó en la pacificación del Reino, que se hallaba revuelto por las continuas asechanzas de bandoleros, piratas, salteadores y delincuentes, que andando por caminos, arboledas, montes y ciudades, saqueaban todo lo que encontraban a su paso. Para conseguir su objetivo, el virrey no tuvo resquemor alguno de violar la legislación foral en repetidas ocasiones (García Martínez, 1980a: 135-183), hecho que suscitó las quejas de los representantes en las Cortes, que Felipe II sólo convocó para Valencia en 1564 y 1585, mientras que Carlos V lo había hecho en 1528, 1533, 1537, 1542, 1547 y 1552. Más tarde Felipe III sólo convocó una vez las Cortes, Felipe IV las reunió en dos ocasiones, y el último de los Austrias en España, Carlos II, no llegó a hacerlo nunca. A las Cortes de 1585 no acudieron por su corta edad los nobles que participarían más tarde en la Academia, aunque algunos de éstos estuvieron presentes 
en las convocadas por Felipe III en 1604. En realidad, la convocatoria de Cortes no tenía más propósito que la solicitud real de ayuda económica para costear las constantes empresas guerreras de los Habsburgo madrileños. Los valencianos solían conceder al rey cien mil libras más los gastos correspondientes -otras diez mil libras-, mientras que el soberano hacía alguna concesión a éstos censurando unas pocas acciones de contrafuero de los virreyes y aceptando la promulgación de fueros y actos de Cortes que aseguraran ciertos privilegios nobiliarios, así como la fortificación de la costa, la vigilancia de los moriscos o el atajo de la violencia bandolera. El apoyo del estamento nobiliario al rey era patente por las numerosas concesiones que hacía a medida que pasaban los años. Aparte de los auxilios económicos a la Monarquía, la nobleza valenciana fue perdiendo su protagonismo social y subyugándose paulatinamente a la castellana.

Carlos V visitó Valencia en 1528 para jurar los fueros, aunque aprovechó la estancia para ennoblecer a muchos y concederles prebendas. En 1564 hizo lo propio Felipe II, y en 1599 entró en Valencia Felipe III, acompañado por su hermana Isabel Clara Eugenia y el valido Lerma, con el fin de jurar como rey de Valencia y aguardar a doña Margarita de Austria, que llegaría al poco para desposarse con el rey español. Casey ha destacado el efecto psicológico del juramento de los fueros (1983: 232). Aquella boda, celebrada por los poetas valencianos y por toda la ciudad, que participó en los festejos y ceremonias, reveló las diferencias existentes entre nobles castellanos, quienes ocuparon todos los lugares principales en los actos de aquellos días, y señores valencianos, más humildes y relegados a un segundo plano, según las anotaciones del dietario de Pere Joan Porcar, quien no oculta su animadversión hacia los nobles castellanos:

\footnotetext{
Dilluns a 10 de maig 1599, entre quatre i cinc hores de la vesprada, entraren en casa de don Jaume Sorell a netejar-li lo pou que los de l'almirant que allí aposentaven i ell també, l'havien embrutat tot de sucietat i bacins. I de la gran pudor, entrà primer un home i se ofegava, i entrà un altre per a ajudar ad aquell i els dos restaren allí morts de la pudor. I casi en totes les cases que estos Grans de castellans han aposentat han fet lo mateix dels pous, i tots los aposientos han emmerdat, i tot ho han derruït i casi fins a tots los panys de les portes han arrancat: esta és la ganància que Sa Majestat nos ha portat a València ab tal bruta gent, i més que l'Hospital General està molt ple de pobra gent perquè totes les quadres a cada part hi ha dos llits, u davant de altre, plens de malalts forasters, lo que no s'ha vist molts anys ha en València (1983: 34-35).
}

La Academia de los Nocturnos nació, por tanto, en un momento en que el Reino de Valencia había perdido su autonomía política, su lengua propia languidecía como vehículo literario, la independencia de la nobleza nati- 
va era ya un espejismo, prisionera de los deseos reales, y su economía y crecimiento demográfico se habían estancado. Tampoco ayudó la situación económica y militar de la Monarquía, sumida en una progresiva crisis, cuyo antecedente más notable hay que buscarlo en 1568. A la rebelión flamenca, se sumó el comienzo de las guerras de religión en Francia y el aumento de la presión islámica en la costa mediterránea. Al mismo tiempo, las cosas no iban mejor dentro del país porque, aparte del encarcelamiento del príncipe heredero don Carlos, se revitalizó el bandolerismo catalán y valenciano, mientras que crecía la peligrosidad de los moros bautizados, que despuntó en las escaramuzas de las Alpujarras, episodio que provocó el desplazamiento clandestino de cristianos nuevos al Reino de Valencia. Asimismo, la economía valenciana de la década de 1570-1580 se resiente por el aumento de la población y la incapacidad de la agricultura del Reino para mantener a ese excedente demográfico. Contribuyó negativamente la sucesión de malas cosechas, inundaciones -especialmente catastróficas fueron las de 1581 y 1589 - y sequías -la de 1582, por ejemplo-, que ayudaron al aumento -constante hasta la centuria siguiente- de la inflación. Así las cosas, Felipe II iba nombrando virreyes para Valencia -el marqués de Mondéjar en 1572, Pedro Manrique de Lara y Girón en 1578, y en 1581 el mentado arriba conde de Aitona-. Recibió este último el gobierno cuando el Reino se hallaba en una situación deplorable. S. García Martínez establece dos períodos en su virreinato, separados por las Cortes de 1585 (1980b: 169). Durante el primero de ellos reprimió el vagabundaje, mantuvo la prohibición de usar armas con pedernal, persiguió a los encubridores de los bandidos, hostigó a criminales, salteadores y bandoleros, y castigó a los responsables de las reyertas nobiliarias. En la segunda etapa señalada intentó con todos los medios restablecer el orden público, para lo que se sirvió de la pragmática dada por Felipe II el 29 de marzo de 1586, y por Aitona en Valencia dos meses después. Castigaba esta ley la negligencia en la persecución de delincuentes, el encubrimiento, la pertenencia a bandas, e incluso a los familiares de los bandoleros. Centradas estas disposiciones en el emergente bandolerismo morisco, intentaron frenar una situación cada vez más difícil de sostener. Hasta tal punto fue eficaz la política del virrey, que S. García Martínez afirma lo siguiente:

Al concluir 1586 la situación del País Valenciano había dado un vuelco espectacular. La política represiva a ultranza había cubierto todos sus objetivos y sólo restaba asegurar las cotas alcanzadas (1980b: 176).

Son años de represión de los moriscos, que fueron castigados despiadadamente por la Inquisición durante el decenio 1585-1595, lapso cronoló- 
gico en que se alcanzó la cifra de 1.266 procesados. Los cristianos nuevos seguían siendo un problema para el Reino y para la Monarquía, porque era imposible mantenerlos aislados de las costas, a pesar de las numerosas pragmáticas que les impedían acercarse a ellas, y por tanto, constituían un valioso apoyo para los piratas desembarcados en el litoral mediterráneo. Al mismo tiempo, muchos señores valencianos se oponían a que se les impidiera poseer armas, como había establecido Felipe II, porque utilizaban a estos vasallos en sus guerras particulares, asuntos de honor y rencillas tradicionales. Aparte de estos hechos, los cristianos viejos fueron demostrando a medida que pasaba el tiempo un mayor odio contra los moriscos, hasta el punto de que las autoridades se vieron obligadas a prohibir insultos verbales y amenazas físicas contra ellos.

La Academia de los Nocturnos, pues, se desarrolló en un momento en que la Monarquía se desmoronaba, porque el antiguo orden feudal destinado a gobernar pequeños territorios no era útil para la administración de un imperio constituido por tierras de cuatro continentes. Los metales preciosos que salían de las entrañas de América no bastaban para mantener las onerosas empresas militares de los Habsburgo, al tiempo que la capacidad económica de los Reinos era limitada y desigual. Diríase, en expresión de P. Vilar, que «desvinculada de la realidad, la España de 1600 prefiere soñar» (1976: 344). En el contexto valenciano, la capital del Reino había dejado de ser Corte renacentista y humanista en 1550, tras la muerte de Fernando de Aragón. Lleva razón en este sentido J. Fuster cuando afirma que la Academia había reconstruido «l'articulació cultural elitista» de una Valencia sin Corte ni mecenazgos (1989: 299). La última década del siglo fue un período de estancamiento económico, al que se sumó un número considerable de problemas relacionados con la violencia, la piratería, los cristianos nuevos y la observancia de los fueros. La nobleza valenciana había perdido su condición de clase dirigente para subordinarse totalmente a los designios de Felipe II, por no hablar del codicioso valido de su hijo. $\mathrm{El}$ advenimiento de la Academia en este contexto hay que entenderlo como respuesta a la situación de crisis que ya se manifiesta en todos los órdenes del vivir. Nobles, religiosos y ciudadanos, siguiendo la tradición nativa de tertulias y reuniones, tanto como el modelo italiano emulado por las academias peninsulares, intentaron mantener la chispa del humanismo en un escenario poco brillante.

La Academia es deudora, en su organización y objetivos, de la sociedad finisecular que la cobijó. La importancia de su obra fue destacada ya por el historiador contemporáneo y académico Gaspar Escolano, quien, con cierta nostalgia, escribió lo siguiente: 
La Academia llamada de los Nocturnos, que como estrellas resplandecieron en aquellas noches valencianas por muchos años, en todas facultades de letras; que si hubiera quien alentara la impresión de tantos y tan copiosos trabajos y los sacara a la luz, sin duda hubiera acaudalado mucha reputación a la nación española con las extranjeras, que ciegamente la tienen por desterrada de semejantes ejercicios de curiosidad (1972: II, col. 531).

$\mathrm{Al}$ redactar su Autobiografía, don Bernardo Catalán dedicó corto espacio a la Academia que presidía. Allí mismo remite al lector a las actas de las reuniones:

Ans de aço, en lo mes de setembre, 1591, nos juntarem uns quants cavallers y amichs y instituhirem una Academia pera exerçitarnos en hobres y actes virtuosos, no posare açi los qui som ni res del sucçes della pues mes llargament se veura en los llibres que estan intitulats de la Academia, aon estan totes les hobres ques feren y fan en ella (1929: 12).

En efecto, redactados los estatutos y establecido el número de sus miembros, la Academia se reunió por primera vez el 4 de octubre de 1591. La vida de la Academia sería larga y salutífera. Se puede dividir el desarrollo de sus actividades en tres etapas cronológicas. La primera se inicia en octubre de 1591 y llega hasta mayo de 1592; la segunda abarca desde octubre de 1592 hasta marzo de 1593; y la última, que comienza en octubre de 1593 y acaba en abril de 1594. Las treinta y dos primeras sesiones corresponden al primer período reseñado, el segundo se desenvolvió entre la trigésima tercera y la sexagésima; y acabó la Academia cuando se hubo cumplido la jornada octogésima octava. Su Presidente leyó la primera noche un «Soneto en alabança de la Academia»:

Ya qu'el silencio grato nos ayuda, y el reposo común tan procurado del general afecto apoderado obra con fuerças de la noche muda.

La del ingenio con razón acuda al noble pensamiento, que alentado del general sosiego, hallará vado a la virtud puríssima y desnuda.

$\mathrm{Y}$ vos estrella nueva, que naçiendo prometéis la riqueza que gozaron en el dorado siglo de Saturno, 
creçed con nueva luz, porque creciendo se illustren los alientos que hos tomaron por norte de su nombre y fin nocturno (1988: I, 72).

El poema de don Bernardo inauguró las sesiones aludiendo a los dos pilares sobre los que se asentaba la Academia: el ejercicio del ingenio y la práctica de la virtud. A esta primera convocatoria asistieron el Presidente, cuyo nombre en la Academia era Silencio; el Consiliario, Francisco Tárrega, conocido por Miedo; el Secretario, Francisco Desplugues, bajo el nombre de Descuido; el Portero, Miguel Beneito, que participaba en las reuniones con el sobrenombre de Sosiego; y los siguientes académicos: Gaspar Aguilar (Sombra), Francisco Pacheco (Fiel), Maximiliano Cerdán (Temeridad), Hernando Pretel (Sueño), Gaspar de Villalón (Tinieblas), y Fabián de Cucalón (Horror). Intervinieron, por tanto, diez académicos en la primera reunión. Éste sería el núcleo inicial de la Academia y el más importante durante su desarrollo. Probablemente ellos fueron también los responsables de redactar los estatutos que comento abajo. En la jornada novena, celebrada el 27 de noviembre de 1591, Sosiego leyó un «Elogio alabando a los fundadores Académicos», donde se menciona, aparte de a los diez académicos de la primera sesión, a Jerónimo de Virués (Estudio), a Juan Fenollet (Temeroso) y al licenciado Escolano (Luz). El 25 de diciembre, Miedo recitó un soneto dedicado «al nacimiento de Christo Redemptor» en que aparecen «todos los nombres allegóricos de los Académicos». Tárrega añadió a la nómina conocida los nombres de Jaime Orts (Tristeza) y Manuel Ledesma (Recogimiento). No menciona, sin embargo, a Luz, quien intervino un poco más tarde -el 15 de enero de 1592-. El Ms. Res. 32, ya citado, contiene un listado de académicos en el que aparecen estos quince arriba mencionados y otros treinta y uno, cuyos nombres copio a continuación: Evaristo Mont (Soledad), el maestro Antonio Joan Andreu (Vigilia), el maestro Gregorio Ferrer (Industria), Gaspar Mercader (Relámpago), Francisco de Villanova (Recelo) -el nombre de este académico está tachado, por lo que su sobrenombre pasaría a don Carlos Boyl-, don Guillén de Castro (Secreto), don Francisco de Castro (Consejo), don Guillem Ramón Catalán (Reposo), López Maldonado (Sincero), don Tomás de Villanueva (Tranquilidad), Pelegrín Catalán (Cuidado), don Joan Pallás (Olvido), el maestro Gaspar Gracián (Peligro), don Matías Fajardo (Oscuridad), el capitán Andrés Rey de Artieda (Centinela), Tomás Cerdán de Tallada (Trueno), don Jaime de Aguilar (Niebla), Pedro Vicente Giner (Cautela), don Guillem Bellvís (Lluvia), Jerónimo de Mora (Sereno), don Luis Ferrer (Norte), el doctor Joan Andrés Núñez (Lucero), micer Joan Joseph Martí (Atrevimiento), 
don Pedro Frigola (Espía), Hernando de Balda (Cometa), Estacio Gironella (Resplandor), el licenciado Lorenzo de Valenzuela (Tiento), Joan de Valenzuela (Asombro) y el licenciado Bartolomé Sebastián (Estrella). En la jornada cuadragésima novena firmó «6 redondillas a una hornera hermosa» un tal Lubricán -'crepúsculo'-, de quien no se revela su identidad. Amén de éstos, intervinieron en algunas sesiones candidatos a académicos o aficionados, como Simón Arias, quien solicitó su ingreso en la Academia sin éxito, aunque leyó algunas composiciones en la jornada trigésima quinta ( $\ll 38$ cuartetos en alabança de la Academia»), trigésima sexta («Redondillas al neblí»), trigésima séptima («Soneto a una ausencia de su zagala»), trigésima novena (Cata que subes pensamiento al cielo), y cuadragésima primera ( «Sátyra contra las grandes narizes»), en que se aprecian sus escasas dotes poéticas. Asimismo se menciona a un fraile de la orden de San Pablo, del que ni siquiera se apunta el nombre, quien también presentó algunas composiciones ante la Academia. En la jornada cuadragésima, Luis Navarro presentó un soneto «A la devoción». Poco después, en la sesión cuadragésima quinta, Vicente Giner leyó tres octavas. Del mismo modo, en la jornada septuagésima primera, el Presidente autorizó a Pedro de Tamayo y al Dr. Núñez -después Lucero- a que leyeran sus coplas. Intervino en la misma condición que los anteriores Melchor Orts en las sesiones sexagésima novena, septuagésima y septuagésima octava. El Dr. Tomás Bux compuso para la Academia septuagésima unas «Estancias a Santa Lucía». El día septuagésimo segundo de la Academia ofreció ocasión a Estebán Cortés de leer un soneto «Al señor Presidente». Cosme Damián Tofiño también compuso varios poemas para los nocturnos -uno de ellos se oyó en la jornada septuagésima séptima, otro en la octogésima, cuando también recitó un romance Eduardo Leyete, etc.-. Parece ser que se reservaban los últimos minutos de algunas reuniones para que los aspirantes, o simplemente amigos, recitaran sus versos. La distribución de los trabajos encargados a cada académico no fue homogénea. Así, mientras que las actas no recogen ninguna obra de Joan de Valenzuela, Francisco de Villanova, el licenciado Bartolomé Sebastián y Joan Pallás, y otros académicos leyeron sus textos en contadas ocasiones - por dar una muestra nombraré a Jaime de Aguilar, a Gaspar de Villalón y a Hernando de Balda-, un pequeño grupo de académicos se reservó la responsabilidad de escribir la mayor parte de la obra de los nocturnos -don Bernardo Catalán, Miguel Beneito, Fabián de Cucalón, por recordar a los más significativos-.

La explicación de los nombres alegóricos de los académicos obedece a razones que se escapan a nuestra comprensión, pero desde luego la elección no era azarosa. Dice Sosiego en el mencionado «Elogio»: 
Pero, porque la fama no se asombre de engrandecer sus nombres levantados, disfraça cada qual su propio nombre;

que como ya los tuvo entronizados su propio nombre gustan de trocalle, por ser en otro nombre celebrados (1988: I, 232).

Repasa este académico a continuación los nombres alegóricos de sus compañeros, aunque las referencias no siempre resultan aclaratorias. El cargo en la Academia de Silencio, trasunto de su posición social privilegida, le concede la admiración y loa de los asistentes. Es el «gran Catalán», el «gran Silencio», «clara lumbre» para los académicos. Miedo es el encargado de fijar el canon literario de la Academia, y por tanto, su papel de consiliario le facilitaría la tarea de censurar las obras presentadas, y de ahí que los escritores sintieran miedo ante su severo juicio. Descuido, al actuar como secretario, debía ser cuidadoso a la hora de recopilar y conservar la obra de la Academia, por lo que tal vez Sosiego afirma que «cansado de verse tan famoso / a descuydarse de la fama viene» (1988: I, 233). Temeroso, con su «ingenio milagroso», conseguirá «mil glorias y renombres», porque es «un temor qu'el ánimo levanta» (1988: I, 233). Luz tiene un significado más claro porque «alumbra su ingenio al de los hombres» (1988: I, 233). Fiel recibe el nombre «por ser tales / su sciencia, su saber y entendimiento, / que sirven de balança a los mortales» (1988: I, 234). Sueño «puede dormir siguramente, / pues lo que hay que saber tiene sabido» (1988: I, 234). Temeridad quiere «honrrarnos por estilo bien cubierto» (1988: I, 234). Horror ha merecido «tan grande nombre / que ha de causar horror al más discreto / ver que a tan alto punto aya subido» (1988: I, 234). Tinieblas deja su «claro nombre» para resplandecer mejor «por las tinieblas de su nombre oscuro» (1988: I, 234). Estudio merece el nombre por ser el «más famoso ingenio» (1988: I, 234). Sombra «quiere qu'el mundo asta su sombra alabe», por ser, a juicio del académico, el mejor poeta de la Academia y uno de los modelos que debían seguir sus miembros, «pues es tal en el mundo su poesía / que todo lo qu'es bueno es sombra suya» (1988: I, 235). En la asignación de los nombres subyacía cierta ironía, difícil de descifrar en algunos casos. No extraña, por tanto, que al académico más dado a la chanza lo llamaran Tristeza. Algunos nombres tienen que ver con la noche, momento en que se celebraban las reuniones: Sombra, Tinieblas, Oscuridad y Lubricán. Otros aluden a la luz: Resplandor y Luz. Un grupo de ellos se refiere a fenómenos atmosféricos o elementos celestes: Trueno, Niebla, Lluvia, Lucero, Cometa, Relámpago y Estrella. Entre las 
alusiones alegóricas, destacan las ideas de miedo -Asombro, Temeridad, Horror, Temeroso, Miedo, Recelo, Peligro y Cautela-y de retiro-Silencio, Sosiego, Recogimiento, Soledad, Reposo, Tranquilidad y Sereno-.

Cabe ahora preguntarse cuál fue el objetivo perseguido con la fundación de la Academia. Según la declaración que se lee en la introducción de los estatutos, los académicos se proponen el ejercicio de la virtud, el cultivo del ingenio y el entretenimiento para desterrar el ocio. Téngase en cuenta que una parte de los académicos tenía menos de treinta años, con lo que el cenáculo valenciano habría perseguido asimismo contribuir a su formación. En este sentido, Pedro Salvá resta importancia a esta última idea ya expresada por Ximeno y opina que la intención de don Bernardo «fue única y exclusivamente la de pasar un rato de solaz cada ocho días, estimulando y ejercitando su ingenio y el de sus amigos» (1869: 15). El juicio de Salvá se fundamenta en la rica galería de obras de los nocturnos cuyo asunto resulta poco edificante. Joan Reglà afirma que la Academia está más cerca de Teodoro Llorente que de Ausiàs March y Juan Luis Vives. Seguramente el parecer del insigne historiador radica en el hecho de que la Academia, enclavada en el marco sociopolítico de Felipe II, emulara los modelos literarios castellanos. En cualquier caso, el parangón aducido por Reglà no tiene en cuenta los fines del cenáculo valenciano ni el calado de la obra creada en él (1989a: 127). Volviendo al razonamiento de Salvá, es difícil explicar sólo con éste el objetivo de la Academia, porque si hubieran pretendido los académicos lo que quiere el escrupuloso bibliófilo, éstos no se hubieran molestado en descubrir su erudición para componer un cuerpo de discursos dedicados a los asuntos más variados. Ahora bien, se pueden distinguir dos capítulos en la instrucción de los asistentes. El primero consiste en el adiestramiento en el arte poética, que comprende la imitación de los modelos tradicionales tanto grecolatinos como castellanos, el dominio de la métrica y la perfección del estilo. En este sentido se desempolva el desideratum humanista de educación del vate, que abarcaba aspectos generales tales como la formación del carácter, la filosofía y la erudición, junto a otros específicos que consistían tanto en el estudio de la lengua, las reglas del arte y la imitación como en la lectura. El aprendizaje de las destrezas universales era cantera de temas para el poeta, mientras que la comprensión de las particulares le garantizaba el desenvolvimiento en el oficio. Sosiego, cuando ofreció a su auditorio el «Elogio» mentado arriba, muestra su deseo de imitar a los académicos porque «el exercicio hará naturaleza» (1988: I, 236). Redundando en esta idea, Estudio reconoce la importancia de la «exercitación» para el estudio de las letras, "porque con el trabajo y continuación se labra y cultiva el entendimiento» (1988: I, 143). Resultaba lógico que un grupo de jóvenes 
nobles se engolfara en la composición de versos, dados el progresivo acercamiento de la nobleza cortesana a la literatura y la necesidad de mantener su status y consideración (Rodríguez de la Flor, 1989: 33). Comparto en este aspecto la opinión de J. L. Canet:

A los académicos valencianos no les interesaba crear una antigua academia que sirviera de marco para la disputa o aprendizaje integral humanístico, sino lo que realmente les importaba era reunirse unos cuantos «ingenios medianos» de la ciudad de Valencia para ejercitarse en unos modelos literarios que sirvieran ante todo a los intereses de la nobleza, para que ésta pudiera desenvolverse con facilidad en ese nuevo espacio cortesano-ciudadano, creando al mismo tiempo una nueva estructura del poder cultural en la propia ciudad (1993: 118).

El segundo capítulo al que he aludido antes radica en la voluntad de la Academia de imbuir a los más jóvenes de la doctrina científica e ideológica imperante en la misma ${ }^{2}$. Por supuesto, esta instrucción ni fue sistemática ni obedecía a un programa preconcebido de altura humanista. De hecho, el tipo de educación que había habilitado el Humanismo utilizaba la poesía sólo como medio y nunca como fin, es decir que interesaba a los instructores que sus discípulos nobles aprendieran los elementos retóricos que intervenían en la creación poética, aunque no era necesario que este proceso educativo desembocara en la elaboración literaria. Leer y escribir ficciones, por ello, era un ejercicio frecuentado por los maestros humanistas para conseguir que sus alumnos se desenvolvieran con facilidad en el

2. Peligro leyó un «Discurso de la discreción spiritual» en la jornada octogésima quinta en que habla del «ejemplo que de todo género de virtud da la congregación de Nocturnos académicos» (Ms. Res. 34 , fol. $211 \mathrm{v}$ ). Se puede entender que el académico considera que la junta de la que él es miembro se constituye como modelo para sus integrantes. Y a su vez, casi tres décadas después, Olivares mostró su preocupación por la educación de los jóvenes, según ha explicado Elliott: «Sólo mediante la educación del individuo a una edad todavía moldeable, podían imbuirse en su ánimo como era debido las virtudes cívicas del servicio y la obediencia. Los jóvenes, se lamentaba en su carta al cardenalinfante [27-IX-1632], no estaban siendo criados de forma correcta. Él había intentado remediarlo mediante la creación del Colegio Imperial de Madrid, pero hacia 1632 resultaba evidente que la nueva fundación constituía un fracaso. Lo que proponía ahora era la creación de academias del estilo de las que podían encontrarse en Francia y la República de Venecia. En la corte, además de la casa de los pajes, por la que le correspondía velar a él en su calidad de caballerizo mayor, debían existir dos de esas academias, y había que fundar otras en Sevilla, Granada, Valladolid, Lisboa, Pamplona y en Aragón. La finalidad de esas instituciones debía ser proporcionar una educación militar y "política" y, según la elaboración de los planes de Olivares que realizaría más tarde una Junta de Educación nombrada a tal efecto, en ellas se debía conjugar el ejercicio práctico de las artes marciales con el teórico de las matemáticas, la geografía, la mecánica, y las artes "políticas y económicas que instruyen el ánimo para el gobierno público y doméstico"» (1990: 448). 
terreno de la Retórica y la Oratoria ${ }^{3}$. Al tratar de qué es más provechoso, el ejercicio de las armas o el estudio de las letras, Estudio se inclina por lo segundo y confía en que los valencianos se ocuparán de que sus hijos sean instruidos en ellas:

[...] Tendrán special cuydado de hazer que las aprendan sus hijos, para que con ellas honrren su nación, aprovechen y authorizen sus personas y crien tales sujetos que puedan pasar adelante esta nueva y bien instituhida ACADEMIA (1988: I, 149).

En el fondo de la Academia subyacían los ideales de la Contrarreforma tamizados por la ordenación social, política y cultural establecida por Felipe II y su representante en Valencia, el virrey Aitona. En efecto, el cenáculo valenciano se organizó emulando los principios políticos rectores de los Habsburgo, que consistían en la subordinación de los intereses del Reino de Valencia a los de la Monarquía, como acostumbraban a denominar entonces al conjunto de los reinos que poseía Felipe II. Es pertinente, por ello, analizar ahora cómo se reprodujeron los tipos sociales de los Austrias en la Academia.

La jerarquización de la Academia es indiscutible dada la presencia de nobles, militares, religiosos y ciudadanos que destacaban por su cultura y formación, ocupando cada uno de estos grupos el lugar que correspondía a su prestigio social y capacidad económica. La información biográfica que se tiene de sus miembros permite agruparlos según el estamento al que pertenecen. La noticia de sus vidas, no obstante, no siempre es completa y segura. Sobre algunos académicos se poseen datos exhaustivos que permiten reconstruir toda su trayectoria vital y literaria, aunque de otros sólo se conoce su participación en las reuniones de los nocturnos. A pesar de ello, se puede estudiar la composición de la Academia con los detalles acopiados hasta ahora.

La nobleza, en sus distintos rangos, ostentaba los principales cargos de la institución, hecho que se daba igualmente en la sociedad civil y militar (Domínguez Ortiz, 1985: 24). Su máximo representante era el Presidente, destacado miembro de una familia valenciana notable. Acumuló durante toda su vida numerosos nombramientos: familiar del Santo Oficio, veedor de la costa del Reino de Valencia, Síndic dels Senyors del Comú de

3. Strosetzki (1997) ha analizado con detenimiento la relevancia de la cultura para el hombre renacentista y el peligro denunciado por humanistas y eruditos de que la nobleza permaneciera ociosa. Acerca de otros aspectos concretos del mismo tema, $c f$. P. Ruiz (1995). Sobre los usos y textos empleados para instruir a la nobleza, $c f$. N. Baranda (1995) y J.-M. Laspéras (1995). 
les Carniceries Mayors, procurador por el Brazo militar en las Cortes de 1604, embajador de éstas ante el rey, caballero de la Orden de Calatrava y corregidor de la ciudad y Reino de León, ciudad donde murió en 1608. Leyó siete discursos en prosa y numerosos poemas religiosos de carácter devoto, entre los que destacan los sonetos que recitó a partir de la jornada décima séptima dedicados al santo de cada día. Entre la alta nobleza también se contaban Luis Ferrer de Cardona, portantveus del gobernador de Valencia y lloctinent y capità general del Reino; y Gaspar Mercader, conde de Buñol, familiar del Santo Oficio y procurador por el Brazo militar en las Cortes de 1604. Como se ha indicado, sustituyó al Presidente en octubre y parte de noviembre de 1593. Mercader leyó cuatro discursos en prosa y una cifra considerable de poemas amorosos, en cuya composición demostraba gran habilidad. Por debajo de ellos se encontraban otros nobles. Guillem Ramón Catalán era primo del Presidente, igual que Peregrín de Catalán, quien participó en las Cortes de 1604 como procurador por el Brazo militar. Este último compuso un discurso en prosa y unos treinta poemas. Los hermanos Cerdán de Tallada y Sancho eran igualmente nobles. Maximiliano asistió en 1604 a las Cortes como procurador por el Brazo militar, fue comisionado ante el rey y capitán de caballos de la costa. Preparó dos discursos en prosa y treinta y cinco poemas. Tomás era jurisconsulto y llegó a ser caballero de las Órdenes de San Jorge y de Montesa, así como vigilante del puerto del Grao. Fabián de Cucalón, barón de Cárcer, fue miembro del Brazo militar en las Cortes de 1604. Tres años después obtuvo el cargo de Justicia criminal de Valencia, y en 1610 era representante ante el Consell de la clase de caballeros y generosos, así como Justicia civil. Francisco Juan Desplugues, señor de la Pobla Llarga, actuaba como Secretario de la Academia, según se ha dicho, y fue igualmente representante del Brazo militar en las Cortes de 1604, Jurat por la clase de los caballeros y generosos, y conseller. Juan Luis Fenollet también era noble, aunque conocemos pocos datos sobre su biografía. Asistió como procurador por el Brazo militar a las Cortes de 1604. Pedro Vicente Giner, procedente de familia noble, ejerció como capitán y sargento mayor. Presentó dos discursos en prosa, amén de los poemas. Joan Pallás, barón de Cortes, consta en el listado de académicos, aunque no hay noticia de que participara en ninguna sesión. Tomás de Villanueva, conde de Castellar y barón de Quesa y Bicorp, ha dejado poco rastro de su vida, a excepción de su participación en la Academia, donde leyó un discurso y algunos poemas. Miguel Beneito pertenecía a la pequeña nobleza urbana, aunque llegó a ser Justicia civil en 1596 y tres años después conseller de la ciudad por la clase de caballeros y generosos. Preparó tres discursos en prosa, aparte de la poesía. Guillén de Castro procedía de familia noble de ascendencia castellana y sirvió en las grandes casas no- 
biliarias. En 1593 fue nombrado capitán de caballos de la costa, en 1601 era procurador general de Carlos Borja, duque de Gandía, y en 1605 entró al servicio del conde de Benavente, virrey de Nápoles, quien en 1607 lo nombró gobernador del castillo de Seyano. Finalmente lo armaron caballero de Santiago en 1623. Se le encargaron cuatro discursos en prosa y leyó poemas tocantes a diversos asuntos. Carlos Boyl, señor de Massamagrell y Farnals, asistió a las Cortes de 1604 como representante del Brazo militar. Guillem Bellvis era también miembro de la nobleza valenciana y fue procurador por el Brazo militar a las Cortes de 1604. Gaspar de Villalón, caballero de la Orden de San Jorge y de Montesa, participó en las primeras sesiones de la Academia. Todos estos nobles habían dejado sus posesiones para trasladarse a Valencia, donde llevaban en gran parte una vida ociosa al tiempo que conseguían algún nombramiento. Sus antepasados habían abandonado sus tierras sobre todo a partir de las sublevaciones agermanadas y de la creación en la ciudad de Valencia de una verdadera Corte a cargo de Germana de Foix, quien alentó la vida palaciega y el ejercicio artístico cortesano. Durante el siglo XVI, no hubo virrey en el Reino que emulara la magnificencia y esplendor de la Corte de la virreina, mantenida por su esposo, el duque de Calabria, cuando ésta falleció. Al casarse éste con doña Mencía de Mendoza, singular e ilustrada dama, el mecenazgo cultural del virreinato continuó hasta 1550, año en que murió Fernando de Aragón. A partir de entonces ninguna corte virreinal consiguió aglutinar a artistas, sabios y profesores, de modo que esta ausencia ralentizaba el progreso de la vida intelectual en Valencia.

El Consiliario Francisco Tárrega representaba al clero en su más alta jerarquía. Doctor en derecho canónico y canónigo de la catedral de Valencia en 1584, fue juez en todas las justas poéticas convocadas en Valencia mientras que vivió. Debió de tener una autoridad literaria inigualable en la Valencia de la época, y por supuesto, en la Academia. Además representaba el contrarreformismo del Patriarca Ribera, quien velaba por que los postulados tridentinos se respetaran en la ciudad del Turia y en todo su Reino. Leyó seis discursos en prosa y numerosos poemas consagrados a diversos asuntos tanto serios como jocosos. Se permitió el canónigo la licencia de escribir sobre temas eróticos, amorosos y burlescos poco adecuados a su condición. El franciscano Antonio Juan Andreu fue catedrático de artes metafísicas y teología en la Universidad de Valencia, donde llegó a ser vicerrector. Gozó de buena fama como predicador y él mismo instruyó a los hijos del virrey Aitona, de quienes era preceptor. Pronunció cinco discursos en prosa. Francisco Castro, hermano de Guillem, entró en los dominicos en agosto de 1592 y sólo participó en la Academia en marzo de aquel año. Gaspar Juan Escolano, eclesiástico y licenciado en teología, fue 
cronista del Reino de Valencia a partir de 1604. Se le encargó en la Academia la composición de cinco discursos en prosa, alguno de ellos de asunto histórico. Gregorio Ferrer, presbítero y doctor en teología, fue catedrático de Súmulas en 1588 y de Qüestions en 1592. Un año después consiguió la cátedra de Filosofía. Compuso nueve discursos en prosa. Lorenzo de Valenzuela, doctor en teología, leyó sólo tres poemas en la Academia. Aparte de éstos, aparece en el listado de académicos un licenciado Bartolomé Sebastián, que no intervino en ninguna ocasión, y el maestro Gaspar Gracián, quien leyó seis discursos en prosa en la Academia. Es posible que ambos fueran religiosos, aunque no hay suficientes datos para confirmarlo.

Fuera de estos dos estamentos permanece un grupo de ciudadanos cultos, quienes despuntan entre los intelectuales de la ciudad. Para quienes no procedían de familias prestigiosas y acaudaladas, la cultura era una forma de subsistencia y reconocimiento, como mostró Cervantes en La fuerza de la sangre 4 . Hay que citar entre ellos a algunos escritores profesionales, cuya experiencia literaria preacadémica era considerable y, a la postre, fundamental para el sostenimiento de la Academia. Andrés Rey de Artieda era doctor en cascun dret además de militar, en cuya condición intervino en el socorro de Chipre, y en las batallas de Lepanto, de Navarino y de Mequinenza. El autor de Los amantes era el escritor más veterano de la Academia. Nacido en 1544, Rey de Artieda se dedicó al ejercicio de las armas y consiguió el grado de capitán, al tiempo que iba cosechando fama por su obra literaria. Leyó un discurso en prosa y algunas composiciones poéticas. Gaspar Aguilar era igualmente un conocido poeta valenciano en la época, cuya trayectoria profesional es ejemplo del literato al servicio de la nobleza. Ocupó el puesto de secretario del conde de Sinarcas y más tarde el de mayordomo de los duques de Gandía. Prolífico y bien dotado para la poesía, se destacó por su inclinación a la escritura de encargo y a la participación en todo evento literario al que fuera convocado. En la Academia se oyeron cuatro discursos suyos en prosa y algunos de los mejores poemas. El castellano Juan López Maldonado había llegado a Valencia acompañando a su ama, doña Tomasa de Borja y Enríquez, señora de las villas de Grajar y Valverde y familiar de los duques de Gandía. A ésta dedicó su Cancionero de 1586. Una vez en la ciudad ingresó en la Academia, donde intervino a partir de marzo de 1592. Es otro caso claro de escritor que sirve a la nobleza, y por esta razón, se ve obligado a escribir sus encargos y halagar su vanidad. Francisco Pacheco sólo asistió a las primeras reuniones de

4. En efecto, Luis a los siete años «ya sabía leer latín y romance y escribir formada y muy buena letra; porque la intención de sus abuelos era hacerle virtuoso y sabio, ya que no le podían hacer rico» (1613: $131 \mathrm{r}-131 \mathrm{v})$. 
la Academia, donde leyó un discurso en prosa y algún poema. Podría ser éste el famoso pintor nacido en Sanlúcar de Barrameda en 1564, porque durante el inicio de la década del noventa se dedicó a viajar por España. Jaime Orts era fecundo poeta valenciano que participó en casi todos los certámenes poéticos de su tiempo, por lo que no podía faltar en la nómina de académicos, a los que leyó un discurso y numerosísimas poesías caracterizadas por su tono burlesco y erótico. Su talante, y seguramente su aspecto físico, le valieron distintas calificaciones de demonio, coco, poeta infernal, etc.

El gremio médico estaba muy bien representado. Joan Andrés Núñez se doctoró en medicina en Valencia en 1589 y fue miembro del Consell de la ciudad en varias ocasiones, así como Juez de apelaciones. Leyó dos discursos en prosa y distintos poemas de poca enjundia. Jerónimo de Virués, hijo del célebre médico Alonso de Virués, también era doctor en medicina. Leyó seis discursos en prosa y algunos poemas. El doctor Tomás Bux intervino como aficionado, según se ha dicho.

Por último, quiero recordar a Micer Juan José Martí, doctor en cascun dret a partir de 1598, y miembro del Consell de Valencia durante ese año. Célebre por su Segunda parte del Guzmán de Alfarache (1602), leyó algunas poesías en la Academia, en la que ingresó en febrero de 1594.

De los datos que he expuesto arriba se deduce que la Academia estaba compuesta por nobles, religiosos y ciudadanos que ejercían como profesores, escritores, médicos o juristas. Entre éstos existe una diferencia de rango considerable. Nobleza y clero monopolizan los cargos de la Academia y se convierten en sus rectores. Téngase en cuenta que durante el reinado de Felipe II ambos estamentos incrementaron el número de sus miembros de forma considerable. Fijan el canon literario, observan la ortodoxia tridentina y reproducen los modelos jerárquicos de la sociedad de Felipe II. Se ocupan casi exclusivamente de la elaboración de los discursos en prosa, de la asignación de sujetos y de la aprobación de los textos que se van a leer y copiar en las actas ${ }^{5}$. Destaca asimismo cierta diferencia de edad. Rey de Artieda, Tárrega, y tal vez Jerónimo de Virués, rondaban los cuarenta o los superaban -es el caso de Artieda-. Por los treinta años estaban Gaspar Aguilar, Antonio Juan Andreu, Miguel Beneito, Guillem Bellvís, Maximiliano Cerdán, Gaspar Escolano, Joan Andrés Núñez y Francisco Pacheco.

5. Tómese nota de la apreciación de Lucero cuando pronuncia su «Discurso alabando las mujeres gordas»: «Muy Ilustres Señores, mucha raçón fuera qu'el señor Presidente midiera los discursos con el talento de quien se encargan, obligando a los que poco leen y tienen poco lugar a que hizieran discursos de poco pelo y menos consideración [...]» (Ms. Res. 34, fol. 195v). Es claro que el Dr. Núñez empleó estas palabras teñidas de ironía como captatio benevolentiae, aunque es cierto que los discursos no se encargaban arbitrariamente. 
Contaban veinte o pocos años más los tres nobles más prestigiosos: Bernardo Catalán, Gaspar Mercader y Luis Ferrer Cardona, mientras que Carlos Boyl no había superado los quince años. Sobre esta escalera cronológica se ha manifestado J. L. Sirera en los siguientes términos:

Las cifras creo que abonan con toda claridad esta idea de que, por encima de las jerarquías y del carácter confraternal de la Academia, la parte doctrinal se reservaba, como mínimo en lo que a la prosa atañe, a los académicos de mayor edad [...]. La importante presencia de nobles en el conjunto de la Academia se ve contrapesada por el hecho de que una parte relevante de éstos (y entre ellos, los de mayor prestigio y poder) se encuentran entre sus más jóvenes integrantes [...]. El contenido mismo de los discursos de estos jóvenes puede ser calificado como de secundario, o menos comprometido. Y en ningún caso tratarán temas de índole política (1993: 138 y 139).

La mayoría de los académicos alcanzó puestos de responsabilidad con posterioridad a su paso por la Academia, lo que se explica por la corta edad que tenían en los primeros años de la década del noventa. Es fácil suponer, por ello, que la asistencia a las sesiones académicas enriqueció la formación de los nocturnos y constituyó el hito más importante de la trayectoria literaria de muchos de ellos.

La Academia se rigió por unas Institutiones que constaban de trece artículos numerados más otro sin numerar -escritos por la misma mano- en que se nombraba Presidente a Gaspar Mercader por ausencia de Bernardo Catalán, que estuvo en la Corte desde el 13 de octubre hasta el 3 de noviembre de 1593. En estos reglamentos se reproduce el principio horaciano de mezclar «lo dulçe con lo provechoso», aunque no se menciona ninguna directriz estilística ni métrica.

La primera consecuencia que se desprende de la existencia de estos estatutos es que la Academia se había constituido según el proceder italiano, de manera organizada y reglamentada, herencia de las reuniones que se celebraban en la vecina Italia, cuyo ejemplo propagó El cortesano de Castiglione. En las normas que redactaron los nocturnos se observa la influencia italiana en el uso de sobrenombres - «ordenamos que todos los académicos ayan de tomar el nombre conforme al de la Academia» (1988: I, 59) (III)-, en el carácter periódico de las reuniones (IV), y en la existencia de unas actas que atesoraban los materiales presentados por los académicos (VI):

Ordenamos que se aya de elegir un secretario, el qual tenga obligación de escrevir en el libro de la Academia todas las obras que en ella se hizieren, assí en prosa como en verso, las quales se ayan de escrivir en la casa donde se tiene la 
Academia y no en otra parte, porque no salga el libro del poder del Sor. Presidente (1988: I, 60).

Asimismo, estos estatutos se pergeñaron al socaire de las directrices del postridentismo. En ese sentido se procuró que todas las materias abordadas se mantuvieran al margen de la herejía, la sátira, la obscenidad, etc., si bien estos objetivos no se cumplieron del todo, pues se leyeron abundantes textos satíricos y eróticos. Algunas pautas, que arraigaron en esta sociedad, contribuyeron al acercamiento de la Academia a las tesis de Trento: fijación de sujetos, cariz religioso y moral de muchas actividades académicas, y obligación de oír misa, que se establece en la primera norma:

\begin{abstract}
Primeramente ordenamos, qu'el primer día que nos huviéremos de juntar para començar el virtuoso exercicio de la Academia, todos juntos o cada qual de por sí, oyamos missa y en ella con mucha devoción nos encomendemos a Dios, porque es bien que en principio de todas nuestras cosas acudamos al qu'es verdadero principio d'ellas (1988: I, 59).
\end{abstract}

Al leer las normas de la Academia, se descubre su carácter presidencialista, que se articula en el seno de un orden jerárquico. Aparte del Presidente, la Academia contó con un Consiliario con quien aquél consultaba sobre asuntos tales como el encargo de sujetos, la recepción de académicos, etc.; un Secretario, quien escribía las Actas; y un Portero, que recibía las peticiones de adscripción a la Academia y las entregaba al Presidente. Las sesiones se celebraban en casa de Bernardo Catalán, a quien los académicos debían respeto y obediencia, por ser el principal noble de la congregación, todo lo que se dispuso en la regla segunda:

Ordenamos que la Academia se aya de çelebrar en las casas del Illustre don Bernardo Cathalán, nuestro muy caro y amado Académico, el qual aya de ser y sea presidente d'ella, prestándole desde agora la obediencia que en semejante caso se requiere (1988: I, 59).

El Presidente tenía la facultad de elegir a aquellos académicos que considerara idóneos para desempeñar cualquiera de los cargos mencionados. El de Consiliario era descrito en el estatuto quinto:

Ordenamos para el buen govierno de la Academia que el señor Presidente aya de nombrar un consiliario con el qual consulte todas las cosas que huvieren de hazer: assí de repartir los sujetos, como de recibir académicos, como de otras qualesquier cosas tocantes a la Academia. Y que al Consiliario se le dé silla al lado del señor 
Presidente y al lector, ni más ni menos, pero con condición que la vez que el Consiliario lea no aya de haver más de dos sillas (1988: I, 60).

Otro tanto ocurría con el Secretario y el Portero, a quienes seleccionaba el Presidente sin necesidad de consultar con el resto de los académicos, como se dice en la norma décima:

Por quanto no será bien que el señor Presidente, para las cosas que son de menos importancia, como son: mudar ex causa los días de la Academia, nombrar Consiliario, Secretario y Portero, tenga necessidad de consultallo con los demás académicos, le otorgamos entero poder y facultad para que lo pueda ordenar y hazer como su gusto fuere, y mudar los dichos officiales a su voluntad, sin consulta ninguna y, faltando alguno de ellos, poner en su lugar a quien fuere servido (1988: I, 60-61).

Emplazadas las sesiones de la Academia los miércoles de todas las semanas, don Bernardo había de repartir para la jornada siguiente los sujetos en verso y encargar el discurso en prosa a uno de los académicos -estatuto IV-:

Ordenamos que todos los académicos se junten un día cada semana, que será el miércoles, y que de una semana para otra esté nombrado un lector, el qual sea obligado a leer una lición de aquello que se le encomendare, de la qual resulte a los oyentes mucha erudición y doctrina, y que a los demás académicos les repartan los trabajos conforme sus ingenios y que sea la repartición a voluntad del señor Presidente y con el parecer y acuerdo del lector que entonces fuere (1988: I, 59-60).

Asimismo se prohibió tajantemente que alguien pudiera presentar obras ante la Academia sin observar la norma anterior (XII):

Ordenamos para mejor regimiento de la Academia que, ningún académico ni otra persona de qualquier calidad que sea, pueda leer obra ninguna en verso ni en prosa, si no fuere el sujeto que se le huviere repartido, sin que primero el $\mathrm{S}^{\text {or }}$. Presidente, o quien su orden tuviere, pase los ojos por ella y dada por buena se pueda leer. Y no siendo assí el $\mathrm{S}^{\text {or }}$. Presidente no dé lugar a que se lea (1988: I, 61).

A pesar de estas indicaciones, se permitió también que el Presidente pudiera delegar en otro académico la tarea de pensar los sujetos de la Academia (XIII):

Por quanto tiene mucho trabajo el Académico que ha de leer el discurso, para prevenirse conforme la calidad de los oyentes y, que el pensar sujetos tales no es 
de menos consideración ni se requiere menos estudio, aliviando de la obligación que tenía el lector en el $4^{\circ}$ capítulo, mejorándole en éste, ordenamos que el $\mathrm{S}^{\text {or }}$. Presidente pueda encomendar al académico que quisiere el trabajo de pensar sujetos, como no sea el que huviere de leer aquella jornada. El qual académico los aya de traher al $S^{\text {or }}$. Presidente un día antes de la junta para que con más acuerdo los reparta (1988: I, 61).

El propio Presidente recibía ad aurem (IX) las propuestas de nombramiento o segregación de académicos (VIII):

Ordenamos que qualquiera persona que pretenda entrar en la Academia (demás de aquellos que somos instituidores d'ella), tenga obligación de hazer una petición y dalla al portero, que será nombrado para que la dé al señor Presidente, el qual consultándola con el Consiliario y los demás académicos le reciba si lo mereciere y si no le despida con palabras de mucho comedimiento (1988: I, 60).

Los académicos estaban obligados a asistir a todas las sesiones y sólo el Presidente podía excusar las ausencias (VII):

Ordenamos que ningún académico pueda dexar de asistir en la Academia el día y la hora que los demás se juntaren, que será miércoles en la noche, so pena de ser tenido por descuydado y de poca constancia si ya no tuviere ligítima escusa, la qual a de ser a conoscimiento del señor Presidente y que, aunque la tenga, sea obligado a embiar la obra que se le havrá repartido (1988: I, 60).

En el caso de que Bernardo Catalán no pudiera participar en alguna de las reuniones, se designaría a otro noble para sustituirlo, al que se le concederían las mismas facultadas que a aquél (XI):

Damos el mismo poder al señor Presidente para que, siempre que por alguna ocasión, assí bien vista, faltare en alguna jornada de las Academias, pueda poner en su lugar al cavallero que quisiere, con tal que sea de los académicos, al qual se le tenga el mesmo respeto y suceda en todas las prerogativas que se le deven al señor Presidente (1988: I, 61).

En definitiva, la presencia de reglas en la Academia de los Nocturnos explica la idiosincrasia de que participa, pero también el deseo de mantener una jerarquía y orden internos que reflejaran el modelo social externo. 


\section{BIBLIOGRAFÍA}

BARANDA, N, «Escritos para la educación de nobles en los siglos XVI y XVII», Bulletin Hispanique, XCVII, 1, 1995, págs. 157-171.

Blasi, F, «La Academia de los Nocturnos», Archivum Romanicum, XIII, 1929, págs. 333-357.

CANET, J. L., «Estructura del saber y estructura del poder: organización y funciones de la Academia de los Nocturnos de Valencia», en E. Rodríguez (ed.), De las academias a la Enciclopedia...,Valencia, Ediciones Alfonso el Magnánimo, 1993, págs. 97-124.

Canet, J. L., E. Rodríguez y J. L. Sirera (eds.), Actas de la Academia de los Nocturnos, Valencia, Ediciones Alfonso el Magnánimo, 1988, 1990, 1994, 1996 y 2000.

Casey, J., El Reino de Valencia en el siglo XVII, Madrid, Siglo XXI, 1983.

Catalán de Valeriola, B., Autobiografía y justas poéticas, precedidas de un prólogo de S. Carreres y de una introducción del barón de San Petrillo, Valencia, Acción Bibliográfica Valenciana, 1929.

Cervantes, M. (de), Novelas ejemplares. La fuerza de la sangre, Madrid, Juan de la Cuesta, 1613.

Domínguez Ortiz, A., Instituciones y sociedad en la España de los Austrias, Barcelona, Ariel, 1985.

Elliott, J., La España imperial (1469-1716), Barcelona, Círculo de Lectores, 1963 [ed. princeps: Londres, Edward Arnold Ltd., 1963].

- El Conde-Duque de Olivares, Barcelona, Crítica, 1990 [1986].

Escolano, G., Décadas de la historia de la insigne y coronada ciudad y Reyno de Valencia, Valencia, Universidad, 1972 [ed. facsimilar de la de Valencia, P. Mey, 1610-1611].

Fuster, J., «Les lletres», en E. Belenguer (coord.), Història del País Valencià, III, Barcelona, Edicions 62, 1989, págs. 287-302.

García Martínez, S., «La repressió a ultrança: el virregnat d'Aitona (1581-1594)», en Bandolers, corsaris i moriscos, Valencia, E. Climent, 1980a.

— «La vida política», en AA.VV., Nuestra Historia, IV, Valencia, Mas Ivars Editores, 1980b.

Laspéras, J.-M., «Manuales de educación en el Siglo de Oro», Bulletin Hispanique, XCVII, 1, 1995, págs. 173-185.

Martí Grajales, F., Cancionero de la Academia de los Nocturnos de Valencia, 4 vols. [reimp. con adiciones y notas del extracto hecho por P. Salvá en Valencia, 1869], Valencia, 1905-1912. 
Porcar, P. J., Coses evengudes en la ciutat i regne de València. Dietario de mosén Juan Porcar, capellán de San Martín (1589-1628), 2 vols., ed. de V. Castañeda Alcover, Madrid, 1934 [cito por la Antología publicada en Valencia, Edicions Alfons el Magnànim, 1983].

ReglÀ, J., «Economia i societat», en E. Belenguer [coord.], Història del País Valencià, III, Barcelona, Edicions 62, 1989a, págs. 97-159.

— «Les estructures polítiques i els esdeveniments», en E. Belenguer [coord.], História del País Valencià, III, op. cit., 1989b, págs. 165-215.

RodríGUEZ DE la Flor, F., Atenas castellana. Ensayos sobre cultura simbólica y fiestas en la Salamanca del Antiguo Régimen, Salamanca, Junta de Castilla y León, 1989.

RuIz, P., «La expulsión de los poetas. La ficción literaria en la educación humanista», Bulletin Hispanique, XCVII, 1, 1995, págs. 317-340.

Salvá, P., Cancionero de la Academia de los Nocturnos de Valencia, Valencia, Imprenta de Ferrer de Orga, 1869.

Sirera, J. L., «El universo cultural de la Valencia de la Academia de los Nocturnos», en E. Rodríguez (ed.), De las academias a la Enciclopedia..., op. cit., 1993, págs. 127-170.

StrosetzKi, Ch., La literatura como profesión. En torno a la autoconcepción de la existencia erudita y literaria en el Siglo de Oro español, Kassel, Reichenberger [ed. alemana: Düsseldorf, Droste, 1987], 1997.

VILAR, P., «El tiempo del Quijote», en Crecimiento y desarrollo. Economía e historia. Reflexiones sobre el caso español, Barcelona, Ariel, 1976, págs. 332-346 [edición francesa: Europe, enero 1956, págs. 1-16].

Zabala, A., La Navidad de los Nocturnos en 1591, Valencia, Castalia, 1946. 